\title{
Poetas y predicadores: Arrepentimiento y puro amor en María Magdalena (c. 1550-1600)
}

\author{
Poets and Preachers: Repentance and Pure Love \\ in Mary Magdalene (c. 1550-1600)
}

\author{
Álvaro Alonso \\ Universidad Complutense de Madrid \\ alvaroalonso@filol.ucm.es
}

\section{RESUMEN}

En este trabajo se estudia un conjunto de textos líricos y de sermones (c. 1550-1600), centrados en la figura de María Magdalena. El personaje es visto como una encarnación del puro amor, es decir, el amor desinteresado que está más allá del miedo al infierno y la esperanza del paraíso. No obstante, ciertos desarrollos de esta idea podían conducir a la heterodoxia, por lo que los autores destacan el papel que el temor y la esperanza han de desempeñar en la vida del cristiano, y en la misma María Magdalena.

Palabras Clave: María Magdalena; puro amor; esperanza; siglo XVI.

\section{ABSTRACT}

In this paper we study a set of lyrical texts and sermons (c. 1550-1600) evolving around the figure of Mary Magdalene. She is regarded as the symbol of pure love, that is, the one beyond either the fear of Hell or the hope of Glory. Nevertheless, further developments of this idea could easily be termed as heterodoxy and so the authors stress the central role that fear and hope have for Christians in general and for Mary Magdalene herself.

Key words: Mary Magdalene; Pure Love; Hope; 16th Century.

\section{INTRODUCCIÓN}

Una tradición que se remonta a los primeros siglos del cristianismo, identifica a María Magdalena con la anónima pecadora que en Lucas, 7 se arroja a los pies de Cristo para pedir su perdón (Biblia Sacra, 1977). La escena evangélica termina con las palabras de Cristo, «Remissa sunt ei peccata, quia multum amavit», y esas palabras, «quia multum amavit», sirvieron para caracterizar al personaje a lo largo de los siglos. Otros episodios de la supuesta biografía de la

Copyright: (C) 2016 CSIC. Este es un artículo de acceso abierto distribuido bajo los términos de una licencia de uso y distribución Creative Commons Attribution (CC-by) España 3.0. 
santa, como su desesperada búsqueda del cuerpo de Jesús en el sepulcro o sus largos años de retiro en Provenza, reforzaron esa imagen de María como modelo de penitencia y de amor a Dios (Saxer, 1959; Walsh y Thompson, 1986; Pinto-Mathieu, 1997; Delicado Puerto, 2011).

Pero cabe preguntarse por la naturaleza de esa penitencia y de ese amor. Una tradición que viene por lo menos desde Casiano distingue tres tipos de creyentes: los que temen la severidad de Dios y lo aman como siervos; los que viven con la esperanza de la recompensa eterna y lo aman como mercenarios; y los que no piensan ni en recompensas ni en castigos y aman a Dios con el mismo amor de caridad, es decir, absolutamente desinteresado, con el que Él los ama. Más simple es otra división (que se encuentra, por ejemplo, en San Bernardo), que agrupa a las dos primeras categorías, las que corresponden al temor y la esperanza, bajo el nombre de «amor mercenario», y reserva para el otro amor, el puramente gratuito, los nombres de «caridad» o «amor de amistad» (Joppin, 1938: 23-45).

En las páginas que siguen, me propongo indagar, en un conjunto de poemas y sermones, qué clase de amor se atribuye a la Magdalena o, lo que es igual, cuáles son los móviles por los que se explica su conversión. Limito mi estudio aproximadamente a la segunda mitad del siglo XVI, y me valgo de la obra de varios poetas de la época (como Medrano y fray Arcángel de Alarcón), así como de los principales cancioneros colectivos del momento: el Cancionero general de la doctrina cristiana y el Vergel de López de Úbeda, y la recopilación Obras spirituales, íntegramente dedicada a la Magdalena (López de Úbeda, 1579 y 1588; Obras spirituales, 1591; Alarcón, 1594; Medrano, 2005). Por lo que se refiere a las obras en prosa, recurro, sobre todo, al célebre texto de Malón de Chaide, La conversión de la Magdalena, pero también a otros de notable importancia, como el de Pedro de Chaves o, aun siendo algo anterior a 1550, el de Santo Tomás de Villanueva (Villanueva, 1572; Malón de Chaide, 1947; Chaves, 2009).

\section{AMOR, PURO AMOR Y CONTRICIÓN}

Como es natural, los textos poéticos, en su mayoría, no ofrecen mayores precisiones sobre los sentimientos de la Magdalena: hablan de amor, sin especificar si se trata de un amor desinteresado, o mercenario, o de una mezcla de ambos. No obstante, el lenguaje apasionado de estos textos sugiere en el personaje un total olvido de sí y, por consiguiente, de los castigos y las recompensas:

— ¿Adónde vais, Magdalena?

-No sé, que no voy en mí:

dichoso salir de sí

y estar en sí, amarga pena (López de Úbeda, 1588: 171r). 
Imágenes como la del fuego (omnipresente en estas composiciones) o la del corazón deshecho, sugieren la idea de un sentimiento avasallador, que no deja lugar a cálculo alguno:

El corazón inflamado, en divino amor ardiendo, por los ojos va saliendo en lágrimas destilado (Obras spirituales, 1591: 61).

Por otro lado, al ser el amor desinteresado más perfecto que el mercenario, puede suponerse que la santa es encarnación del primero y no del segundo.

Algunos textos, no obstante, son más explícitos. Encuentro tres composiciones en las que se habla no sólo de «amor» (o de «fuego» o de «amoroso fuego») sino de «puro amor». El primero de esos poemas es el que comienza «Hirió Magdalena el duro pecho», incluido sin indicación de autor en las Obras spirituales. Los versos explican cómo la pecadora lavó sus pecados con las lágrimas:

Las manchas de la edad vana y perdida, al puro amor rendida, lavó con llanto de dolor cansado (Obras spirituales, 1591: 46).

La interpretación de esos versos depende de lo que se entienda por «puro amor»: una expresión que, en este contexto, puede entenderse de tres maneras diferentes:

a) El sintagma «puro amor» sirve habitualmente para referirse al amor que Dios siente hacia los hombres: puesto que la Divinidad nada tiene que temer o esperar del género humano, ese amor se caracteriza por ser puramente gratuito (CORDE: s.v. puro amor). Los versos citados significarían, por tanto, que la Magdalena lloró sus culpas conmovida por el generoso amor que Cristo le mostraba.

b) Al menos desde el siglo XV, la expresión se aplica también el amor desinteresado que el hombre puede sentir hacia Dios. El Arcipreste de Talavera lo explica ya con toda claridad: «Dios todopoderoso [...] debe ser amado no por miedo de pena, que a los malos perpetua dará, salvo por puro amor e dilecçión de Él» (CORDE: s.v. puro amor). Los anónimos versos de las Obras deberán entenderse entonces en el sentido de que la Magdalena se arrepintió por puro amor, es decir, no por temor al infierno ni esperanza de la gloria, sino de forma totalmente desinteresada.

c) Puesto que los amores juveniles de la santa habían sido carnales, «puro amor» podría entenderse como amor espiritual, libre de toda connotación sexual.

El contexto no es lo suficientemente preciso, y cualquiera de las tres interpretaciones es posible en estos versos.

La misma ambigüedad presentan unos versos del Cancionero de López de Úbeda, en los que la voz poética dialoga con la pecadora: 
Su puro amor [el de Cristo] el alma te ha encendido, que si tu amor humano le ha enojado con otro amor divino le has servido (López de Úbeda, 1579: 121v).

«Su puro amor el alma te ha encendido»: de nuevo son posibles tres interpretaciones, según se entienda el posesivo «su»:

a) «El puro amor que Cristo te muestra ha encendido tu alma»

b) «El amor desinteresado que sientes hacia Cristo ha encendido tu alma»

c) «Un amor espiritualizado hacia Cristo (y no carnal como los anteriores) te ha encendido el alma».

Más preciso parece, en cambio, el siguiente pasaje, en el que la voz lírica habla ahora con Cristo:

Perdonando mostráis vuestra clemencia, amando al que os amó, vuestra justicia, que el puro amor con puro amor se paga (López de Úbeda, 1579: 122v).

La idea de que «el puro amor con puro amor se paga» se utiliza normalmente en un contexto religioso muy preciso: puesto que Dios ama gratuitamente a los hombres, éstos deben corresponderle con un amor igualmente desinteresado (Lacoste, 2007: 46). En estos versos el planteamiento se invierte, pues aquí es Dios quien corresponde a la Magdalena, pero, en todo caso, lo que está en juego no es la pureza sexual de esos amores, sino su gratuidad. Así pues, al menos en una de las tres ocasiones en las que aparece, la expresión «puro amor» debe entenderse en el sentido doctrinalmente muy preciso de «amor que nada tiene que ver con la esperanza del premio o el temor del castigo». En los otros dos poemas, tal interpretación es posible, pero no obligada.

Otro término que sitúa al penitente más allá de los móviles interesados es el término «contrición», que aparece en alguno de estos textos (por ejemplo, Obras spirituales, 1591: 66). La palabra, como se sabe, es también muy precisa y designa el dolor de haber ofendido a Dios por ser quien es, sin consideración a las penas o las recompensas eternas. Es el arrepentimiento desinteresado, lo mismo que el puro amor es el amor gratuito.

\section{SUPOSICIONES IMPOSIBLES}

Entre los poetas que vengo considerando, la formulación más llamativa del amor gratuito es la que se encuentra en el poema de Francisco de Medrano «De una peña se despeña». El texto, escrito en redondillas y correspondiente a la producción juvenil del autor (Rodríguez-Moñino, 1969), pone en boca de la Magdalena una larga confesión de sus pecados que termina con una súplica a Cristo: 


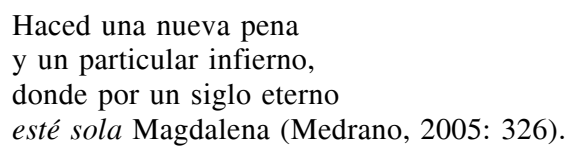

¿Por qué la Magdalena ha de querer un infierno para ella sola? El deseo de la santa es excepcional y no lo encuentro en otros textos poéticos, pero se explica gracias a un pasaje del Flos sanctorum de Villegas (1591):

¿No hubiera sido mejor, Dios mío, aver dado con mi alma en los infiernos, para que allí ella sola se perdiera, y que no haya sido ocasión de que tantas otras se perdieran? (Villegas, 1591: 232v).

$\mathrm{Al}$ asumir como suyos los pecados de sus amantes, la Magdalena quisiera ser la única condenada, pero su propio castigo habría de ser entonces excepcionalmente severo.

Tras admitir que sus pecados deberían conducirla al castigo eterno, se esperaría que el personaje apelara a la misericordia divina para obtener el perdón que, en estricta justicia, no merece. Pero en Medrano, la oración de la Magdalena prosigue de una forma sorprendente:

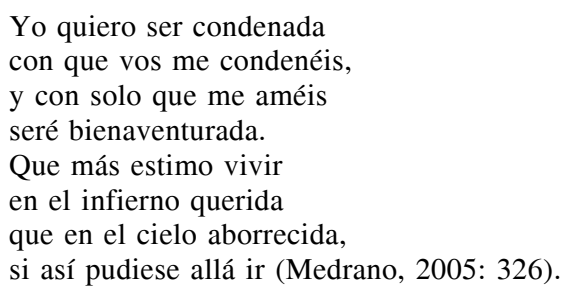

Las dos estrofas constituyen una expresión suprema de amor desinteresado, aunque formulado de manera paradójica: si tal cosa pudiera concebirse, la penitente preferiría el infierno con el amor de Dios al paraíso sin él. Estamos ante una de esas suposiciones que los textos franceses de los siglos XVI y XVII llaman suppositions impossibles o imaginations de chose impossible (Terestchenko, 2000: 53). A través de ellas se expresa el puro amor de forma muy intensa, pero también se toma conciencia de las dificultades conceptuales a las que se enfrenta la noción de amor gratuito.

Suposiciones imposibles de esta naturaleza se encuentran ya antes de Medrano. Así, Gabriele Fiamma comenta en los siguientes términos su propio soneto «Qual danno, qual paura o qual tormento»:

Dice che s'innamora tanto mentre contempla le piaghe del Salvatore, che vorrebbe più tosto essere nelle pene dell'inferno, se per impossibile si potesse essere nell'inferno et essere in grazia di Dio, che essere senza alcun travaglio lontano dalla sua grazia (Fiamma, 1573: 162).

El texto de Fiamma era bien conocido en España (Morreale, 1989), así que 
me parece muy probable que Medrano lo hubiera leído. Pero no es necesario suponer esa influencia concreta, ya que el argumento era relativamente frecuente (Huff, 1948: 57). En los mismos ambientes jesuitas en los que se movía el poeta, y a pocos años de distancia, se encuentra una hipótesis parecida en San Francisco de Sales:

En sorte que si, par imagination de chose impossible, il [un ser humano lleno de puro amor] savait que sa damnation fût un peu plus agréable à Dieu que sa salvation, il quitterait sa salvation et courrait à sa damnation (Sales, 1969: 770).

No obstante, este tipo de hipótesis es raro en prosa, y excepcional en verso. De hecho, en los poemas sobre la Magdalena de la época, no encuentro otra formulación parecida. Incluso ampliando el horizonte, y tomando en consideración la poesía religiosa en su conjunto, tampoco se encuentran muchos más ejemplos. El más famoso es el Soneto a Cristo crucificado (Blecua, 1984: 175-176; Hatzfeld, 1955: 46-51; López-Baralt, 1975), para el que no resulta fácil señalar textos paralelos. Los estudios de Asensio y Bataillon sobre el soneto muestran sus puntos de contacto con San Bernardo, Catalina de Siena, Valdés y fray Juan de Ávila (Asensio, 1950; Bataillon, 1964). Por su parte, Margherita Morreale lo relaciona con el soneto de Fiamma al que ya he hecho referencia (Morreale, 1989), y Huff aduce numerosos textos poéticos en relación con la idea del amor desinteresado. Pero ninguno de estos trabajos menciona ni el poema de Medrano, ni ningún otro en español que se exprese a través de una «hipótesis imposible».

Los versos de Medrano, por tanto, no carecían de originalidad poética, ni de cierta audacia doctrinal. Comentando el soneto A Cristo crucificado, Bataillon intenta explicar su anonimia por motivos doctrinales:

¿Circularía anónimamente esta poesía por miedo a la acusación de iluminismo? No es del todo absurdo pensarlo, aun cuando el sentido del soneto sea intachablemente ortodoxo (Bataillon, 1964: 427).

Pero para una mirada malintencionada o miope las cosas podían no ser tan claras, ya que en este tipo de cuestiones la frontera entre la ortodoxia y la heterodoxia era, con frecuencia, muy sutil. De tal forma, concluye Bataillon, que al abordar estos problemas, convenía extremar la prudencia.

Esas mismas consideraciones pueden aplicarse también a los versos de Medrano. El discurso de su Magdalena, aun cuando fuera «intachablemente ortodoxo», no dejaría de despertar muchos recelos.

\section{AMOR, TEMOR Y ESPERANZA}

El creyente que se mueve por puro amor no piensa ni en las penas ni en las recompensas eternas. Coherentes con esa idea, los poemas sobre la Mag- 
dalena son muy parcos en sus menciones al infierno, aunque no las excluyen por completo. Ya hemos visto cómo en Medrano el personaje ve abiertas las puertas del infierno, pero allí esa mención no inspiraba temor y se resolvía, paradójicamente, en una intensa afirmación de puro amor. Pero otros pasajes son menos serenos. De pronto, en la relación de amor entre Cristo y la pecadora arrepentida, irrumpe la figura del demonio y, con él, la amenaza de la condenación. Así, el poeta Juan Solórzano le recuerda a la pecadora que sus cabellos eran una trampa de la que ha conseguido escapar:

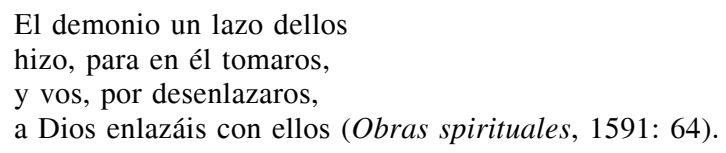

Los versos invierten, de manera muy significativa, el tópico de los cabellos de la Magdalena como una cadena o lazo con los que atrapa, seduciéndolos, a los hombres:

Delgadas hebras de oro, que cadenas / a tantos fuiste, por mi mal gobierno (Padilla, 1585: 232v).

Y con sus rubios cabellos, / que a tantos han enlazado (López de Úbeda, 1588: $171 v)$.

Y con las hebras de oro le enjugaba / que a tantos enlazaron por engaño (Medrano, 2005: 214).

Ahora, la seductora se ha convertido en víctima y sus propios cabellos, en una añagaza de Satanás. Sólo utilizándolos para secar los pies de Cristo, la pecadora alcanza su perdón y se libera del peligro de condenarse eternamente.

En otros versos, Juan Bautista de Bivar se dirige a la penitente para tranquilizarla:

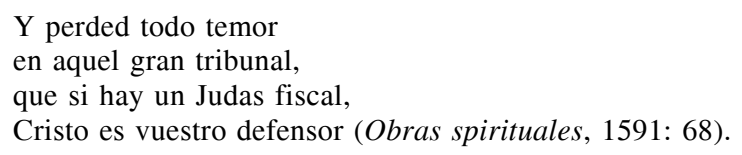

El centro de gravedad del poema se ha desplazado del amor al temor, y la imagen de Cristo como amado ha sido sustituida por esta otra de Cristo como defensor que pleitea ante el fiscal. Algunas expresiones apuntan muy indirectamente a la idea de un castigo ultraterreno: «culpa y pena», «absuelve», «fue reparada» (Obras spirituales, 1591: 43; López de Úbeda, 1588: 168r y 1579: 122v). No obstante, esas rápidas alusiones, y los escasos pasajes más extensos, quedan oscurecidos por los que hablan de amor, fuego y corazones destilados en lágrimas.

Bastante más peso tienen las referencias a una felicidad ultraterrena. Una y otra vez los textos vuelven sobre la gloria que ha de alcanzar la pecadora 
gracias a su arrepentimiento (López de Úbeda, 1588: 170v; Obras spirituales, 1591: 43, 48-50, 54, 60). De manera que los dos móviles interesados no funcionan simétricamente, al menos desde el punto de vista poético: mientras que el temor al castigo se menciona muy pocas veces, como si cuadrara mal con el puro amor de la Magdalena, la esperanza del paraíso convive sin problemas con la noción de amor gratuito. De hecho, un énfasis exclusivo en la noción de amor desinteresado podía ser peligroso. Podía conducir $-\mathrm{y}$ de hecho condujo en ciertos planteamientos heterodoxos- a un descrédito de la esperanza, es decir, de una de las virtudes teologales (Joppin, 1938: 136; Hillenaar, 1967: 198). De forma más o menos deliberada o intuitiva, los textos poéticos vuelven a dar al concepto el relieve que le asignaba la ortodoxia.

En algunas composiciones el planteamiento se complica, y a la noción de esperanza se añade la de fe:

Enviándoos Él bonanza, caridad os tiene en vela, y a la $f e$ dando la vela, tomáis puerto de esperanza (Obras spirituales, 1591: 67).

La idea de que la Magdalena se mueve por las tres virtudes teologales constituye, como veremos, un tópico. Su intención, sin duda, era evitar que la noción de caridad (es decir, de amor desinteresado) alcanzara un protagonismo exclusivo en la figura de la santa, y en la mente del lector.

Una inquietud parecida parece mover a fray Juan de Alarcón en su Vergel de plantas divinas. Allí, su poema sobre la Magdalena, «Amor soberano y sacrosanto» (Alarcón, 1594: 51v-55r), va inmediatamente precedido por otro dedicado a la caridad, «Do buela el pensamiento». Esa organización no puede ser casual y, sin duda, obedece a la idea de que el amor desinteresado encuentra una de sus más altas encarnaciones en la figura de Magdalena. El segundo poema actúa, por tanto, como una suerte de ejemplo, que permite concretar en un personaje los conceptos abstractos del primero. Pero tras subrayar de esa forma la relación entre la pecadora arrepentida y el amor desinteresado, el poeta no olvida las otras virtudes:

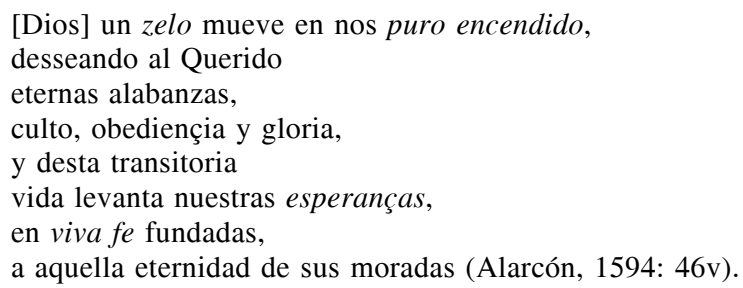

Domina, naturalmente, el lenguaje del amor («zelo puro encendido», «El Querido»), pero se termina con una referencia a la esperanza y la fe. 


\section{LOS PREDICADORES: AMOR, PURO AMOR Y CONTRICIÓN}

Al igual que los poemas, los más conocidos sermones de la época sobre la conversión de la Magdalena insisten en el amor como móvil principal de la pecadora arrepentida. Santo Tomás de Villanueva, Pedro de Chaves, José Acosta y, sobre todo, Malón de Chaide convierten al personaje en una encarnación del amor más encendido, expresado a través de las mismas imágenes que en la poesía lírica: el fuego, la herida (Malón de Chaide, 1947, II: 131; Chaves, 2009: 104), el corazón deshecho en lágrimas (Álvarez, 1591: 301; Malón de Chaide, 1947, II: 197, 213; Chaves, 2009: 94).

La mayor extensión y empeño doctrinal de los sermones hace que puedan explicitar más claramente el carácter desinteresado del amor de María Magdalena. Pedro de Chaves recurre a la expresión «puro amor» para explicar que la santa es el modelo de arrepentimiento perfecto

quando el pecador, no por temor de la pena como ya es dicho, sino por el puro amor que ya Dios ha infundido en su ánima se duele en lo interior (Chaves, 2009: 93).

$\mathrm{Y}$ recalca que «no fue movida la penitencia desta amorosa mujer de ningún temor [...], sino con verdadera contrición mezclada con ardiente amor» (Chaves, 2009: 94).

La expresión «puro amor», sin embargo, es más bien rara, pues los predicadores prefieren el término «caridad». Así, fray Tomás de Villanueva inicia su sermón De diva Maria Magdalena con un largo elogio de la caridad, la primera de todas las virtudes, y fray José Acosta recuerda que nadie puede salvarse sin caridad, pero señala como casi inalcanzable el ejemplo de María Magdalena (Acosta, 1596: 530).

\section{LOS PREDICADORES. SUPOSICIONES IMPOSIBLES}

Son muy pocos los ejemplos que encuentro de suposiciones imposibles también en prosa. En un arrebatado párrafo de Malón de Chaide, la pecadora exclama:

¿Qué quiero yo, Dios mío, bien mío, gloria mía, sin Vos en el cielo? Si Vos, esperanza mía, no estáis allí, todo me fuera noche, todo tristeza, todo infierno; y si a Vos, vida de mi alma, os tuviese en el infierno, me sería dulce paraíso, allí tendría yo mi gloria (Malón de Chaide, 1947, I: 75).

Aunque no idéntica, la formulación es parecida a la que hemos visto en Medrano: el (imposible) infierno con Dios y con su amor sería preferible al (no menos imposible) paraíso sin Él.

Algo más adelante, el predicador cita a San Anselmo, destacando el carácter meramente hipotético («si fuese posible») de la situación que imagina: 
Dice San Anselmo en el Libro de las semejanzas que, si fuese posible, antes querría ir a padecer todas las penas del infierno sin pecado que al paraíso con él (Malón de Chaide, 1947, I: 118).

Una formulación paradójica, aunque, como señala el propio predicador no sea estrictamente imposible, es la que adelanta Santo Tomás de Villanueva cuando afirma que preferiría amar a Dios y no verlo, que verlo y no amarlo: «potius eligerem amare non videndo quam videre non amando» (Villanueva, 1572: 367).

\section{LOS PREDICADORES. AMOR, TEMOR Y ESPERANZA}

A comienzos del siglo XV, San Vicente Ferrer hace decir a la Magdalena: «Donchs, ¿yo dapnada só? ¡Oo mesquina! ¡Yo dapnada seré!» (Ferrer, 1932: 193). Son las primeras palabras que pronuncia la santa tras escuchar a Cristo, como si el temor al infierno fuera el primero de los motivos que la llevan al arrepentimiento.

Ya hemos visto que en el siglo XVI el énfasis recae sobre la noción de amor, pero no faltan nunca referencias a las penas infernales. En la misma circunstancia que la de San Vicente - es decir, después de oír por primera vez a Cristo- la Magdalena de Malón de Chaide se siente invadida por el temor: «Mira la justicia divina, ve a Dios airado, cerrado el cielo, el infierno abierto, y arder aquel fuego sempiterno que la esperaba» (Malón de Chaide, 1947, II: 86). En Pedro de Chaves, Cristo dice a la pecadora:

No sigas, pues, sus appetitos [los de la carne], porque por la delectación que recibieras en un momento con ello, padesceréys ambos pena que no tiene final [...] Teme en quántos lloros vernás (Chaves, 2009: 73).

Y, en efecto, la Magdalena le suplica:

Si yo miserable merezco por mis pecados gravíssima pena eterna, apello para tu inefable misericordia, confiando que no seré condenada [...] Señor, confúndelos, que querían mi ánima para llevarla al infierno (Chaves, 2009: 73).

Vale la pena recordar que el propio Chaves había señalado que «no fue movida la penitencia desta amorosa mujer de ningún temor», lo que muestra hasta qué punto el diseño del personaje vacila a la hora de presentarlo como encarnación del puro amor o del amor mercenario. Por otra parte, puede compararse esta línea de argumentación con la que seguía Medrano: en el poeta, la pecadora reconoce que merece el infierno, y acepta con alegría la decisión divina. Chaves, más convencional, hace que la pecadora tema el infierno y apele a la misericordia de Dios para evitar el castigo que confiesa merecer.

Aunque no se refieran directamente a la santa, no son raros los pasajes en los que se habla de la necesidad de imitarla para escapar del infierno. Así, Pe- 
dro de Chaves aconseja a sus oyentes que sigan el ejemplo de la Magdalena, pues de lo contrario «despeñándonos vamos a parar al profundo del infierno, donde no hay orden en la vida [...] ni falta de espanto perdurable» (Chaves, 2009: 89). Por su parte, Malón de Chaide, aparte de mencionar ocasionalmente el infierno, dedica completos los capítulos 43 a 45 de su obra para recordar la necesidad de temer a Dios y sus castigos (Malón de Chaide, 1947, III: 31-55).

Aunque no son demasiado frecuentes, esos pasajes introducen una pequeña modificación en la figura de la santa en relación con los textos poéticos: el amor, sin duda, sigue siendo el motivo principal, pero el temor adquiere una importancia algo mayor. La diferencia se explica por la diferencia de géneros: en la lírica, el poeta puede prescindir de los argumentos persuasivos basados en el infierno, a los que no puede renunciar del todo el predicador que quiere influir sobre sus oyentes. Un ejemplo extremo de cómo el propósito aleccionador puede modificar la figura de la santa lo constituye el texto de fray Alonso de Cabrera Consideraciones del jueves después del Domingo de Pasión. De la conversión de la Magdalena, a las públicas pecadoras (Cabrera, 1906: 341-347). El sermón habla poco de la Magdalena, y es, en realidad, un feroz alegato contra las prostitutas. Sin embargo, para ejemplificar su argumentación Cabrera recurre a la figura de la santa y su conversión: «una mujer pública, pecadora, como quien dice una leona, se puso en razón, entendió lo que le convenía» (Cabrera, 1906: 344). Entrar en razón y atender a la propia conveniencia es exactamente lo contrario de lo que pide el amor desinteresado. A una penitente llena de amor, e incluso extáticamente fuera de sí, se opone esta figura razonable y calculadora, que el predicador entendió que debía de resultar más persuasiva para su auditorio. A continuación, Cabrera describe minuciosamente las penas del infierno, y se detiene en los cuerpos abrasados y desgarrados por los demonios, así como en la desesperación de los condenados, que maldicen el día de su nacimiento y a quienes los engendraron. Y concluye, volviendo a la Magdalena: «Esto fue lo primero que esta pecadora conoció de lo sobrenatural» (Cabrera, 1906: 346). Se trata de un caso excepcional, pero ilustra en qué medida las exigencias de las circunstancias y la naturaleza del auditorio podían alejar al predicador de la representación del puro amor.

Si estos textos no olvidan el temor al infierno, aun más destacan la esperanza de la felicidad en la vida futura. No sólo: en algún caso, el sermón permite argumentar y justificar lo que en la lírica simplemente podía insinuarse, es decir, la legitimidad, e incluso la necesidad, de mantener viva la esperanza. En su sermón sobre la Magdalena, Santo Tomás de Villanueva comienza planteando el problema esencial del puro amor: un amor basado en la promesa de la vida eterna parece desvirtuar su verdadera esencia y convertirse en amor mercenario: «huiusmodi affectio mercenaria videtur» (Villanueva, 1572: 372r). La expresión «amor mercenario», que no he podido documentar entre los poetas, tiene, según hemos visto, una larga tradición como antítesis del 
«puro amor». Pero Santo Tomás intenta rescatarlo, siquiera parcialmente, al recordar que hay tres razones, que no son recíprocamente excluyentes, de amar a Dios: «Primo quia iustum, secundum quia debitum, tertio quia proficuum» (Villanueva, 1572: 368r). Así que se puede amar a Dios por su propia perfección (quia iustum) pero también con la esperanza de la futura salvación (quia proficuum). No parece casual que, al igual que los poetas en sus versos, Santo Tomás en su teoría tome en consideración la esperanza del paraíso pero no el temor al infierno: como si fuera más fácil, y más necesario, resolver la tensión entre puro amor y esperanza que no entre puro amor y temor.

En la práctica de los predicadores, esa idea se expresa en referencias a la beatitud eterna, o en una vuelta al tópico de la Magdalena como representación no solo del puro amor a Dios, es decir, de la caridad, sino también de las otras dos virtudes teologales. Así, Pedro de Chaves afirma que la Magdalena vino a lavar los pies de Cristo «con verdadera fe, con verdadera esperanza y con ardentísima caridad»; y con minuciosidad escolástica puntualiza: «La fe lo lavó [a Cristo]. La caridad lo ungió. Y la esperança lo glorificó» (Chaves, 2009: 86-90).

\section{CONCLUSIONES}

María Magdalena aparece tradicionalmente como la encarnación del amor hacia Dios. En los textos poéticos y en los sermones el carácter desinteresado de ese amor se expresa de varias formas:

1) A través de un léxico muy pasional, que parece excluir todo cálculo en la conversión de la pecadora.

2) Mediante el papel secundario que se asigna al infierno $y$, en menor medida, a las recompensas futuras.

3) Mediante el uso de expresiones como «contrición», «caridad», «puro amor» que, por su propia definición, sitúan al creyente más allá del miedo y la esperanza.

4) A través del uso de hipótesis imposibles. Este último procedimiento es muy raro y, en poesía, excepcional. Sólo lo encuentro en Medrano, que se distingue así entre los escritores de su época por la originalidad poética (y, en cierto modo, doctrinal) de su planteamiento.

No obstante, esos textos no conceden nunca un protagonismo exclusivo al amor desinteresado: en ocasiones, el amor cede el paso al temor; el léxico de la pasión al judicial; la presencia de Cristo a las alusiones al demonio. La caridad, eje de todos estos textos, convive con la fe y, sobre todo, con la esperanza. Algunas de esas vacilaciones se explican por una indeterminación no deliberada. Es bien conocido el pasaje del Quijote I, 31, en el que Sancho se explica al respecto: «Con esta manera de amor he oído yo predicar que se ha de amar a Nuestro Señor, por sí solo, sin que nos mueva esperanza de gloria 
o temor de pena. Aunque yo le querría más amar y servir por lo que pudiese». Poetas y predicadores suelen presentar a la Magdalena como ejemplo del amor «sin esperanza de gloria o temor de pena», pero en ocasiones la representan amando a Dios «por lo que pudiese».

No obstante, a veces esas referencias que se apartan del amor desinteresado son muy conscientes. Precisamente porque su figura encarnaba como pocas la idea del puro amor, era las más adecuadas para reflexionar sobre la belleza, pero también sobre los límites, los peligros y las paradojas de ese concepto.

\section{BIBLIOGRAFÍA CITADA}

Acosta, José (1596). Canciones in Quadragesimam. Salamanca: Juan y Andrés Renaut.

Alarcón, Arcángel de (1594). Vergel de plantas divinas en varios metros espirituales. Barcelona: Jaime Cendrat.

Asensio, Eugenio (1950). «El soneto "No me mueve mi Dios..." y un auto vicentino inspirados en Santa Catalina de Siena», Revista de Filología Española. 34, pp. 125-136.

Álvarez, Antonio (1591). Segunda parte de la silva espiritual. Salamanca: Juan y Andrés Renaut.

Bataillon, Marcel (1964). «El anónimo del soneto "No me mueve mi Dios...”», en Varia lección de clásicos españoles. Madrid: Gredos, pp. 419-440. Biblioteca Románica Hispánica, II, 77.

Biblia Sacra iuxta Vulgatam Clementinam (1977). Madrid: Biblioteca de Autores Cristianos.

Blecua, José Manuel (1984). Poesía de la Edad de Oro, II. Barroco. Madrid: Castalia. Clásicos Castalia, 136.

Cabrera, Alonso de (1906). Sermones. Miguel Mir (ed.). Madrid: Bailly Baillière e hijos. NBAE, 3.

Chaves, Pedro de (2009). Libro de la vida y conversión de la Santa María Magdalena. Jordi Aladro (ed.). Barcelona: Publicaciones de l'Abadía de Montserrat. Scripta et Documenta, 83 .

CORDE. Real Academia Española. Banco de datos. CORDE [en línea] Corpus Diacrónico del Español http://www.rae.es [ref. de 17/03/2014].

Delicado Puerto, Gemma (2011). Santas y merectrices. Herederas de la Magdalena en la literatura de los Siglos de Oro y la escena inglesa. Kassel: Reichenberger. Teatro del Siglo de Oro, 115.

Ferrer, Vicente (1932). Sermons, II. J. Sanchis Sivera (ed.). Barcelona.

Fiamma, Gabriele (1573). Rime spirituali. Venecia: Francesco de' Franceschi.

Hatzfeld, Helmut (1955). Estudios literarios sobre mística española. Madrid: Gredos.

Hillenaar, Henk (1967). Fénelon et les jesuites. La Haya: Martinus Nijhoff. Archives Internationales d'Histoire des Idées, 21.

Huff, Mary Cyria (1948). The Sonnet «No me mueve mi Dios». Its Theme in Spanish Tradition. Washington D.C.: The Catholic University of America. Studies in Romances Languages and Literatures, 33 .

Joppin, Gabriel (1938). Fénelon et la mystique du pur amour. París: Gabriel Joppin.

Lacoste, Jean-Yves (2007). Dictionnaire critique de théologie. Olivier Riaudel y Jean-Yves Lacoste (3. ${ }^{a}$ ed.). París: Presses Univesitaires de France.

López-Baralt, Luce (1975). «Anonimia y posible filiación del soneto "No me mueve..."», Nueva Revista de Filología Hispánica. 24, pp. 243-266. 
López de Úbeda, Juan (1579). Cancionero general de la doctrina cristiana. Alcalá de Henares: Juan Íñiguez de Lequerica.

López de Úbeda, Juan (1588). Vergel de flores divinas. Alcalá de Henares: Herederos de Juan Gracián.

Malón de Chaide, Pedro (1947). La conversión de la Magdalena. Félix García (ed.). Madrid: Espasa-Calpe, 3 vol. Clásicos Castellanos, 104, 105, 130.

Medrano, Francisco de (2005). Diversas Rimas. Jesús Ponce Cárdenas (ed.). Sevilla: Fundación José Manuel Lara.

Morreale, Margherita (1989). «Apuntaciones para la lectura del soneto anónimo "No me mueve, mi Dios, para quererte" y del de Gabriele Fiamma "Qual paura, qual danno o qual tormento"», en Alberto Porqueras-Mayo, José Carlos de Torres y Francisco Mundi Pedret (ed.), Estudios sobre Calderón y el teatro de la Edad de Oro. Homenaje a Kurt y Roswitha Reichenberger. Barcelona: PPU, pp. 419-456. Estudios, 9.

Obras spirituales de diversos en prosa y verso en el día de la fiesta de S. María Magdale$n a$, recogidas por el muy Reverendo P.F. Ioan Bru de la Madalena (1591). Roma: Domingo Basa.

Padilla, Pedro de (1585). Jardín espiritual. Madrid: Querino Gerardo.

Pinto-Mathieu, Élisabeth (1997). Marie Madelaine dans la littérature du Moyen Âge. París: Beauchesne.

Rodríguez-Moñino, Antonio (1969). «Los romances de don Francisco de Medrano», Boletín de la Real Academia Española. 49, pp. 495-550.

Sales, Francisco de (1969). Oeuvres. André Ravier (ed.), con la colaboración de Roger Deves. París: Gallimard. Bibliothèque de la Pleiade.

Saxer, Victor (1959). Le Culte de Marie Madeleine en Occident des origines à la fin du moyen âge. Auxerre-París: Cavreuil, 2 vol.

Terestchenko, Michel (2000). Amour et désespoir. De François de Sales à Fénelon. París: Du Seuil.

Villanueva, Tomás de (1572). Conciones sacrae. Alcalá de Henares: Juan de Lequerica.

Villegas, Alonso de (1591). Flos sanctorum y Historia general de la vida y hechos de Jesucristo. Toledo: Juan Rodríguez.

Walsh, John K. y B. Russell Thompson (1986). The Myth of the Magdalen in Early Spanish Literature (with an edition of the Vida de Santa María Madalena in Ms. H-I-13 of the Escorial Library. Nueva York: Lorenzo Clemente.

Fecha de recepción: 24 de marzo de 2014.

Fecha de aceptación: 8 de octubre de 2014. 